\title{
Pathogenesis and Potential Strategies for Prevention and Treatment of Septic Shock: An Update
}

\author{
M. P. Glauser, D. Heumann, J. D. Baumgartner, \\ and J. Cohen
}

From the Division of Infectious Diseases, Department of Internal
Medicine, Centre Hospitalier Universitaire Vaudois, Lausanne.
Switzerland: and the Departments of Infectious Diseases and of
Bacteriology and Medicine, Hammersmith Hospital and Royal
Postgraduate Medical School. London, United Kingdom

\begin{abstract}
Septic shock is mediated by complex interactions of cells, cytokines, and humoral pathways. Clinical therapeutic strategies aimed at inhibiting selected pathways have been efficacious in subsets of patients. Experimental studies focusing on the activities of single cytokines have contributed to the understanding of the complex pathophysiology of septic shock. More precise delineation of the roles of each mechanism contributing to pathogenesis will permit the identification of subsets of patients who might benefit from particular therapeutic strategies and will guide the development of additional approaches to prevention and treatment.
\end{abstract}

Septic shock is a clinical syndrome that has become increasingly important in the last 40 years. The condition is most common among hospitalized patients, particularly those with underlying diseases. Although patients with diseases caused by "classic" gram-negative pathogens (such as plague or typhoid fever) may present with the clinical picture of septic shock, it is only since the 1950s-with the increasing incidence of disease caused by gram-negative bacilli of the normal host flora-that the sepsis/septic shock syndromes have been defined. We believe that these definitions (table 1) $[1,2]$ are satisfactory: the identical incidences of shock and death in the various clinical studies using these criteria indicate that similar groups of patients are being enrolled. However, the definitions need to be improved to take into account various factors that are important for predicting outcome, including underlying diseases and appropriateness of antibiotic and medical/surgical treatment. A modified scheme for classification of these syndromes-known as systemic inflammatory response syndrome (SIRS) and multiple organ dysfunction syndrome (MODS) [3]-is currently being discussed, but no consensus has yet been reached.

Septic shock has traditionally been recognized as a consequence of gram-negative bacterial infection, but it may also be caused by gram-positive organisms and fungi and probably by viruses and parasites as well. Table 2 summarizes the organisms isolated and the mortality documented in three recent studies of sepsis syndrome/septic shock $[2,4,5]$.

This article is adapted with permission from two previously published articles: Glauser MP, Zanetti G, Baumgartner JD, Cohen J. Septic shock: pathogenesis. Lancet 1991;338:732-6; and Cohen J. Glauser MP. Septic shock: treatment. Lancet 1991;338:736-9.

Reprints or correspondence: Prof. M. P. Glauser, Division of Infectious Diseases, Department of Internal Medicine, Centre Hospitalier Universitaire Vaudois, 1011 Lausanne, Switzerland.

Clinical Infectious Diseases 1994:18(Suppl 2):S205-16

(C) 1994 by The University of Chicago. All rights reserved.

$1058-4838 / 94 / 1802-0036 \$ 02.00$
Gram-negative bacteria were isolated in $30 \%-80 \%$ of cases and gram-positive bacteria in $5 \%-24 \%$. In one prospective study of sepsis syndrome [2], no etiologic agent was identified in more than half of all cases. Notably, the severity of septic shock, as reflected by mortality, did not depend on the type of organism responsible.

Initial studies of the pathophysiological features of septic shock concentrated on the interactions of lipopolysaccharide (LPS) from the gram-negative bacterial cell wall with various humoral pathways. However, attention is now focused on the central role of macrophages, endothelium, and cytokines that are released upon stimulation by most if not all of the recognized agents of septic shock (figure 1). In this review. we address the known humoral pathways that are activated during septic shock, and we discuss the role of cytokines. particularly tumor necrosis factor (TNF) and interleukin I (IL-1). Although the current emphasis is on the activation of macrophages and cytokine production. we think that evidence for direct activation of humoral pathways by microbial constituents remains relevant. We also review the mechanisms by which LPS interacts with macrophages, citing experimental and clinical studies evaluating the potential of antiLPS and anticytokine agents in therapy for septic shock.

\section{Bacterial Cell-Wall Components and Septic Shock}

The exotoxins produced by some bacteria (e.g., exotoxin A produced by Pseudomonas aeruginosa or toxic shock syndrome toxin produced by some strains of Staphylococcus aureus) can initiate septic shock. However, the bacteria themselves-and in particular their cell wall components-are primarily responsible for the development of septic shock. These components are potent activators of numerous humoral pathways and also of macrophages and other cells involved in inflammatory processes.

The prime initiator of gram-negative bacterial septic shock is endotoxin, an LPS component of the bacterial outer mem- 
Table 1. Definitions of sepsis syndrome and septic shock.

\begin{tabular}{|c|c|}
\hline Sepsis syndrome & Septic shock \\
\hline $\begin{array}{l}\text { Clinical evidence of infection } \\
\text { Tachypnea* } \\
\text { Tachycardia }^{\dagger} \\
\text { Hyperthermia or hypothermia } \\
\text { Evidence of inadequate organ perfusion, } \\
\text { including one or more of the } \\
\text { following: } \\
\text { Hypoxemia } \\
\text { Elevated plasma lactate concentration }^{\text {Il }} \\
\text { Oliguria }^{*}\end{array}$ & $\begin{array}{l}\text { Sepsis syndrome with } \\
\text { hypotension** }^{* *}\end{array}$ \\
\hline
\end{tabular}

* Respirations, $>20 / \mathrm{min}$; if mechanically ventilated, $>10 \mathrm{~L} / \mathrm{min}$.

${ }^{\dagger}$ Pulse, $>90 / \mathrm{min}$.

‡ Core or rectal temperature, $>38.3^{\circ} \mathrm{C}$ or $<35.6^{\circ} \mathrm{C}$.

${ }^{1} \mathrm{PaO}_{2} / \mathrm{FlO}_{2}, \leqslant 280$ (without other pulmonary or cardiovascular disease as the cause).

"Exceeding upper limits of normal for the laboratory.

\# Documented urine output, $<0.5 \mathrm{~mL} / \mathrm{kg}$ of body weight for at least 1 hour (in patients with catheters).

** Sustained decrease in systolic blood pressure to $<90 \mathrm{~mm} \mathrm{Hg}$ or drop by $>40 \mathrm{~mm} \mathrm{Hg}$ for at least 1 hour when volume replacement is adequate, the patient is taking no antihypertensive medication, and other causes of shock (such as hypovolemia, myocardial infarction, and pulmonary embolism) are absent.

brane. Endotoxin circulating in the blood appears to be a predictor of poor outcome in some clinical settings (e.g., meningococcemia [6]), but the levels of endotoxin required to trigger the cascade of events in septic shock may vary greatly. Indeed, it has been observed that bacterial products other than LPS may profoundly increase the host's sensitivity to endotoxin, thereby rendering toxic otherwise-harmless levels [7]. Hence, the measurement of endotoxin has not yet become standard clinical practice.

The outermost part of the endotoxin molecule consists of a series of structurally and antigenically diverse oligosaccharides that are responsible for the $O$ serotype of gram-negative bacteria. Internal to the $\mathrm{O}$ side chains are the core oligosaccharides, which have similar structures in common gramnegative bacteria. Lipid A, which is bound to the core oligosaccharide, has a highly conserved structure and is responsible for most of the toxicity of endotoxin. However, some types of natural lipid A and synthetic lipid A analogues that have different sugar and acyl residues are less-or not at all-toxic both in vitro and in vivo. This observation has led to the development of lipid A analogues that can block the toxic effects of endotoxin or act as endotoxin antagonists $[8,9]$.

\section{Antibodies to Endotoxin}

The O-specific oligosaccharide side chains of endotoxin are highly immunogenic. Antibodies to these side chains inhibit the effects of endotoxin and, by virtue of their opsonophagocytic properties, eradicate the endotoxin-producing organism. However, because these antibodies are specific for a particular O serotype, their clinical application is limited. An alternative approach has been to develop antibodies to the structurally conserved core glycolipid of endotoxin or to lipid A in the hope that these antibodies will offer cross-reactivity or cross-protection against the toxic component of all gram-negative bacteria. In initial clinical trials conducted 10 years ago, antisera or preparations of hyperimmune polyclonal intravenous immunoglobulin were used [10-13]. While the results of these trials suggested a benefit and stimulated subsequent trials of monoclonal antibodies, they did not specifically demonstrate that antibodies to lipid A were responsible for the protection observed.

Recently, clinical trials of two monoclonal antibodies to the core glycolipid of endotoxin have received considerable attention $[14,15]$. In a prospective, randomized, placebocontrolled trial of E5 (a murine monoclonal IgM antibody to lipid A), 486 patients with suspected gram-negative sepsis

Table 2. Frequency of isolation of various types of microorganisms and corresponding mortality in three recent studies of sepsis syndrome/septic shock.

\begin{tabular}{lccc}
\hline & \multicolumn{3}{c}{$\begin{array}{c}\text { Frequency of isolation/mortality among } \\
\text { patients with indicated condition* }\end{array}$} \\
\cline { 2 - 4 } Type of microorganism & $\begin{array}{c}\text { Sepsis syndrome } \\
(n=382)\end{array}$ & $\begin{array}{c}\text { Septic shock } \\
(n=119)\end{array}$ & $\begin{array}{c}\text { Septic shock } \\
(n=89)\end{array}$ \\
\hline Gram-negative bacteria & $30 / 31$ & $60 / 49$ & $80 / 55$ \\
Gram-positive bacteria & $16 / 29$ & $24 / 89$ & $5 / 2$ \\
Mixed or fungi & $3 / 5$ & $16 / 75$ & $4 / 2$ \\
Not documented & $53 / 30$ & $\ldots$ & $10 / 11$ \\
Total & $100 / 30$ & $100 / 63$ & $100 / 47$ \\
\hline
\end{tabular}

* Figures are percentages.

$\dagger$ Data are from [2].

${ }^{ \pm}$Data are from [4].

Data are from [5]. 


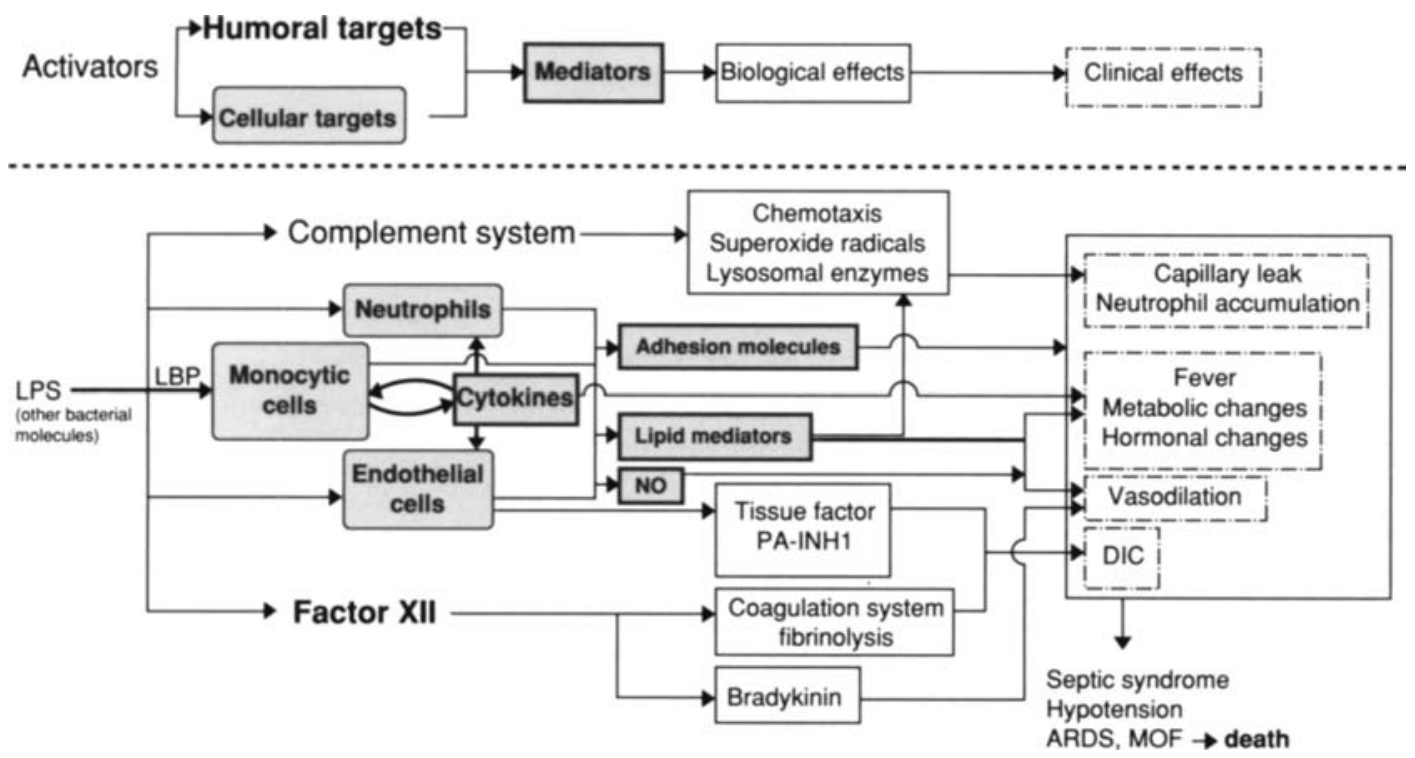

Figure 1. Interaction of humoral factors and cytokines in the pathogenesis of septic shock. LPS = lipopolysaccharide; LBP $=$ LPS-binding protein; PA-INHI = plasmin activator-inhibitor $\mathrm{I}$; DIC = disseminated intravascular coagulation; $\mathrm{ARDS}=$ adult respiratory distress syndrome; $\mathrm{NO}=$ nitric oxide; and $\mathrm{MOF}=$ multiple organ failure.

received either placebo or two intravenous doses of E5 (2 $\mathrm{mg} / \mathrm{kg}$ ) 24 hours apart [14]. The two groups of patients were reasonably well matched, although the unavailability of scores on the Acute Physiologic and Chronic Health Examination (APACHE) II for 203 patients represented a potentially important source of bias. Of the 468 evaluable patients, 316 had a documented gram-negative infection; 179 of these 316 patients presented with shock. Among the 137 patients who did not present with shock, treatment with E5 was associated with significantly lower 30-day mortality $(P=.03)$ and with significantly more frequent resolution of major morbidities (i.e., complications of shock such as disseminated intravascular coagulation $[\mathrm{DIC}]$ and acute renal failure) $(P=.04)$ than was placebo administration. However, no differences in mortality were found between E5-treated patients and placebo recipients who presented with shock or between E5-treated patients and placebo recipients who did not have gram-negative sepsis. Administration of E5 was found to be safe; it did cause an increase in the level of anti- body to murine immunoglobulin in approximately one-half of patients, but the titer was usually low and of no clinical importance.

Since this study suggested that E5 was effective in a subgroup of patients defined retrospectively, a second multicenter study was conducted to verify the finding prospectively. A total of 847 patients without shock were enrolled. The favorable results of the first study were not confirmed: treatment with E5 did not affect survival among the 530 patients with documented gram-negative sepsis. However, a favorable-albeit statistically insignificant-trend was noted in the subgroup of patients in whom gram-negative sepsis was associated with major morbidities, such as DIC and renal failure [16]. A third trial of E5 is under way.

A clinical trial was also performed with HA-1A, a human monoclonal antibody to lipid A. In a study similar in design to that described for E5, patients with suspected gram-negative infection were randomized to receive either an albumin placebo or a single 100-mg intravenous dose of HA-I A [15]. 
Of 543 patients enrolled in the study, 317 had microbiologically documented gram-negative infections; 117 of these 317 patients had had sterile blood cultures at randomization. HA-1A did not reduce mortality either in the overall study population or in the 117 patients with nonbacteremic gramnegative infections. However, mortality did decrease with treatment among the 200 patients with gram-negative bacteremia $(P=.014)$. While this difference in mortality was also noted among the 101 patients with gram-negative bacteremia who presented with shock at enrollment, no such difference was found among the 99 patients with gram-negative bacteremia who did not present with shock. These data contrast with the findings from the first study of E5, in which patients appeared to be protected whether or not they were bacteremic but only when they were not in shock.

This report of reduced mortality in a subgroup of patients given HA-lA led to the licensure of the product in some European countries. However, in the United States, the Food and Drug Administration did not approve this product for several reasons, including (1) changes in the protocol during the clinical trial; (2) the documentation of significant differences only in subgroups of patients; and (3) possible imbalances favoring the test drug at randomization of the patients [17]. Therefore, a second study that focused on patients with gram-negative bacteremia and shock was initiated. During this trial the manufacturer voluntarily withdrew HA-1 A from the market in Europe because of excess mortality in patients without gram-negative bacteremia [18].

These disappointing results with the two monoclonal antibodies to lipid $\mathrm{A}$ are, perhaps, not totally unexpected in light of the studies that led to their development. First, in the original experiments testing the hypothesis that cross-protection could be provided by antibodies to core glycolipid of endotoxin, killed bacteria from a rough-cell-wall mutant strain of Escherichia coli O111 (strain J5) were used for the immunization of animals or humans in order to obtain polyclonal antisera. Although some studies showed protection with polyclonal antisera to $\mathrm{J} 5$, it was impossible to show definitively that protection was attributable to cross-protective antibodies. Indeed, a favorable outcome could not be correlated with antibody titers in either of the two clinical studies done with human polyclonal antisera to $\mathrm{J} 5([10,11]$ and $J$. D. Baumgartner, unpublished data). By solubilization of the core glycolipid in a physiological manner to circumvent nonspecific binding [19], the $\mathrm{J} 5$ antisera used in one study were later shown to contain IgG and IgM antibody to $\mathbf{J} 5$ at a titer only threefold higher than that in control (preimmune) serum; furthermore, these antisera contained no more antibodies to lipid A than did the control serum [20]. Moreover, it now appears that antibodies to $\mathrm{J} 5$ are highly specific for $E$. coli $\mathrm{J} 5$ and that they do not cross-react with endotoxin from other bacteria. Hence, the mechanisms of protection by antisera to $\mathrm{J} 5$ remain unknown. Nevertheless, this approach with polyclonal sera raised against rough structures of LPS laid the groundwork for the development of therapeutic monoclonal antibodies to core glycolipid.

Second, it now appears that clinical trials with these monoclonal antibodies to lipid A were initiated before the immunologic reactivity of these antibodies for LPS substructures was recognized. Since the first disclosure of the possible efficacy of E5 and HA-1A in patients with septic shock [14, 15], many studies have been undertaken to define the reactivity of these antibodies for LPS. In studies by Fujihara et al. [21] and Mascelli et al. [22], HA-1A reportedly bound to lipid A, rough LPS structures, and some preparations of smooth LPS; however, Baumgartner could not confirm such reactivity [23]. Thus the specificity of these antibodies for lipid A is uncertain, in part because immunoglobulins-especially those of the IgM isotype-tend to bind nonspecifically to both the highly amphophilic core oligosaccharide of LPS and lipid A molecules.

It has also been suggested that HA-1A lowers levels of endotoxin by mediating the clearance of LPS via complement-dependent binding of LPS to complement receptor expressed on erythrocytes and neutrophils [24, 25]. Similarly, E5 was shown to bind to lipid A, to rough LPS, and to 15 preparations of smooth LPS isolated from various strains of gram-negative bacteria $[26,27]$. However, neither HA-1A nor E5 was able to neutralize LPS in vitro, as assessed by the limulus lysate test, by a mitogenic assay for murine splenocytes, or by measurement of the production of cytokines in human whole blood [28].

Studies with HA-1A in vivo have yielded inconclusive results. Initially, HA-l A was reported to be protective in mice when used unpurified (as hybridoma fluid) [29]; however, a purified monoclonal antibody obtained from the same clone was not protective in similar experiments and did not suppress endotoxin-induced production of TNF in vivo [30]. A similar failure of HA-1A to protect mice from LPS-induced death was recently reported [31]. More important, in recent experiments with dogs, HA-1 A did not alter levels of bacteremia or endotoxemia and was actually associated with a decreased rate of survival [32]. E5, initially studied in vivo by Young et al. [33], was subsequently shown to be beneficial in a model of pseudomonas sepsis in neutropenic mice [34].

The discrepancies in these results of in vitro and in vivo studies stressed the need for extensive characterization of antibodies to core glycolipid before the initiation of clinical trials.

\section{Activation of Pathways Other Than Cytokines by Cell Wall Components}

Numerous humoral mediators of sepsis have been identified so far, and it is likely that more will be discovered. These mediators act through complex synergistic and antagonistic interactions. LPS in the blood activates the coagulation and complement cascades and induces a broad array of mediators 
from macrophages and other cells, including endothelial cells.

The alternative complement pathway can be activated experimentally by LPS and gram-positive bacterial cell-wall components. The classic pathway is activated mainly by complexes of cell wall components and antibodies. The anaphylatoxins $\mathrm{C} 3 \mathrm{a}$ and $\mathrm{C} 5 \mathrm{a}$, which are produced as a result of activation of these pathways, are responsible for a series of inflammatory events that have been implicated in the pathophysiology of septic shock. C5a has been directly associated with TNF and LPS in hemorrhagic necrosis [35]. Complement components induce vasodilation and increased vascular permeability, which can result in hemodynamic changes, aggregation of platelets, and aggregation and activation of neutrophils-all processes that have been implicated in the pathogenesis of the adult respiratory distress syndrome [36]. The subsequent release of arachidonic acid derivatives, cytotoxic products of molecular oxygen, and lysosomal enzymes exerts additional local vasoactive effects on the microvasculature and causes endothelial cell cytotoxicity, which results in capillary leakage. An increased concentration of activated complement has been associated with a fatal outcome in septic shock of both gram-positive and gram-negative origin [37].

It is well known that arachidonic acid metabolites cause vasodilation, platelet aggregation, and neutrophil activation, which may contribute to the pathogenesis of septic shock. These substances are found in increased concentrations after experimental challenge with endotoxin and during septic shock in patients [38]. The role of inhibitor/antagonists of the pathways of arachidonic acid metabolism in the treatment of septic shock is being investigated.

Activated neutrophils, a key element in the inflammatory response, probably play an important part in the pathogenesis of septic shock by contributing to vascular and tissue injuries. Strong evidence indicates that neutrophils are activated either directly by LPS or indirectly through the action of cytokines [39]. As a result, activated neutrophils may damage tissues by releasing oxygen metabolites and lysosomal enzymes, or they may cause microemboli after aggregation. Activated leukocytes adhere to one another, to endothelial cells, and to tissues through interactions of receptors (on endothelial cells) and ligands (on inflammatory cells) that are mediated by specific adhesion molecules (figure 2). The adhesion process is essential to most functions of leukocytes (including chemotaxis, phagocytosis, and cytotoxicity [40]), and blocking of the adhesion process by monoclonal antibodies prevents tissue injury and improves the survival rate in animal models of septic shock [41].

Two humoral factors are currently being evaluated for their role as mediators of septic shock: platelet-activating factor (PAF) and nitric oxide (NO). The infusion of endotoxin induces the release of PAF, a potent phospholipid mediator that leads to autocatalytic amplification of cytokine release.
PAF is a mediator of inflammation caused by macrophages. neutrophils, platelets, and endothelial cells in response to injury (figure 2). Elevated levels of PAF have been found in models of endotoxin-induced hypotension and endotoxininduced lung injury in rats $[42,43]$. Many antagonists to PAF exist [44]. The first data from a randomized clinical trial of the efficacy of a PAF antagonist in severe sepsis have recently been reported [ 45 ]. In this study 262 patients received either placebo or the PAF antagonist. Mortality decreased by 42\% with PAF antagonist treatment in a subset of 119 patients with documented gram-negative sepsis ( $57 \%$ vs. $33 \% ; P$ $=.011$ ). A confirmatory study focusing on gram-negative sepsis is now in progress.

Hypotension during septic shock may reflect increased synthesis of the potent vasodilator NO. Considerable information is now available on the activity of NO in vitro [46]. Upon LPS challenge, NO is produced mainly by macrophages, endothelial cells, smooth muscle cells, and the liver. Although LPS-induced release of NO by macrophages appears to take several hours, endothelial cells react within minutes-a phenomenon that may contribute to the rapid decrease in blood pressure associated with endotoxic shock [47]. An increasing number of reports deal with the inhibition of this pathway in animal models, but the precise role of NO in septic shock remains unclear [48]. Activity of NO has been detected in experimental gram-negative sepsis [49] and in patients with the sepsis syndrome [50]. While NO blockade in animals has been reported to be beneficial in some studies [51, 52], it has also been found to be detrimental [53]. Treatment with $N$-monomethyl-L-arginine, which blocks NO synthesis, transiently restored blood pressure and systemic vascular resistance in two patients in whom conventional therapy failed [54]. While NO has potentially deleterious effects in endotoxemia, a critical level of locally produced NO is needed to maintain vascular tone. Therefore, more experimental and clinical studies must explore the role of NO in septic shock and delineate the potential for its inhibition in patients.

Factor XII (Hageman factor) in the coagulation cascade has long been known to play a central role in the pathogenesis of septic shock. It is activated equally efficiently by peptidoglycan residues and teichoic acid from the cell wall of gram-positive organisms-e.g., S. aureus and streptococci (including pneumococci)—and by LPS and lipid A from gram-negative bacilli $[55,56]$. Through activation of Factor XI, activated Factor XII triggers the production of tissue factor both by the intrinsic coagulation pathway and by endothelial cells and macrophages; in turn, tissue factor activates the extrinsic coagulation pathway (figures 1 and 2 ). The activation of these pathways through these various stimuli may lead to consumption of coagulation factors and DIC. Moreover, the activation of the contact system by LPS-activated Factor XII (i.e., activation of Factor XII when it comes in contact with negatively charged surfaces, such as those of 


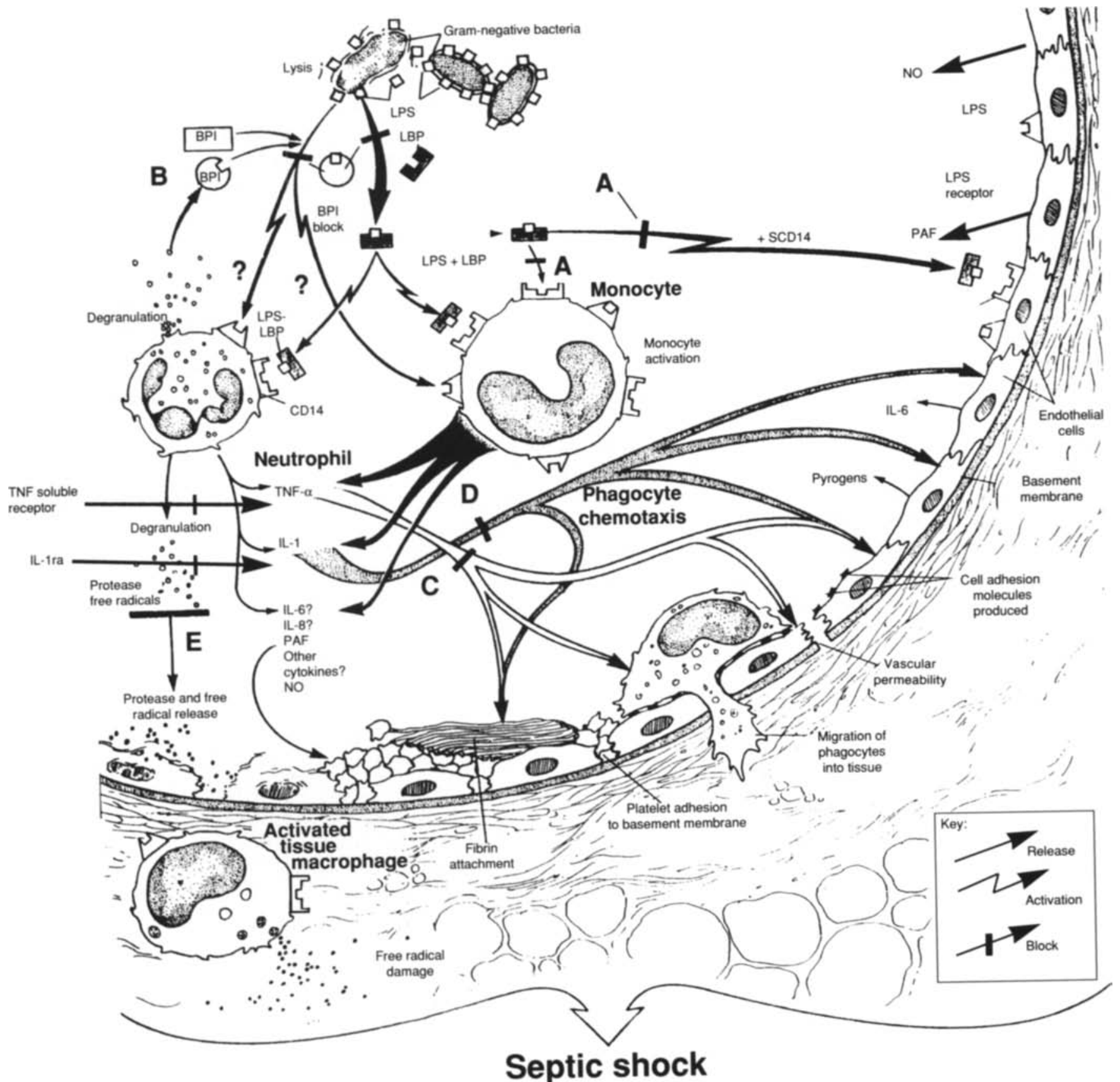

Figure 2. Experimental approaches to blocking septic shock. $(A)$ Monoclonal antibodies to LPS prevent LPS from activating inflammatory reactions. $(B)$ Bactericidal/permeability-increasing protein (BPI), a protein from neutrophil granules, binds LPS. Neither BPI nor antibodies to LPS function when gram-positive organisms invade the bloodstream. (C) TNF- $\alpha$ is inhibited by antibodies or soluble TNF- $\alpha$ receptors. $(D)$ IL-1 is blocked by soluble IL-1 receptors or IL-1 receptor antagonist (IL-l ra), a naturally occurring human protein. (E) Tissue damage later in the septic shock cascade is minimized by protease inhibitors and free-radical scavengers or agents blocking other cytokines, including IL-6 and IL-8. LBP = LPS-binding protein; PAF = platelet-activating factor; NO = nitric oxide; and SCD14 = soluble CDI4.

organisms or substances) results in the conversion of prekallikrein to kallikrein. In turn, kallikrein cleaves high-molecular-weight kininogen to release bradykinin, a potent hypotensive agent [57]. The hypotension and DIC of bacteremia may be mediated-at least in part-by the activation of the contact system via the release of bradykinin and the activa- tion of Factor XI. Recently, a monoclonal antibody to Factor XII was used to block contact activation in baboons; the results showed that the contact system contributes to hypotension but not to DIC in lethal bacteremia [58]. The fact that tissue factor produced upon stimulation of macrophages and endothelial cells by LPS plays a major role in inducing 
DIC is indicated by the prevention of LPS-induced DIC by antibody to tissue factor in animals $[59,60]$. Evidence also exists that protein $\mathrm{C}$ can be activated during gram-negative bacteremia [61] and that activated protein $C$ can prevent the coagulopathic and lethal effects of $E$. coli infusion in baboons [62].

Finally, it is widely recognized that vascular endothelium plays an active role in the development of septic shock. The systemic effects of high doses of intravenously administered TNF or IL-1 into animals include hypotension, decreased systemic vascular resistance, vascular leak, and infiltration of polymorphonuclear leukocytes (PMNs) into tissues [63]. Enhancement of the expression of adhesion molecules on endothelial cells by TNF and IL-1 facilitates PMN margination. TNF and IL-1 increase the procoagulant activity of endothelium and depress the expression of fibrinolytic activity; these changes result in a trend towards intravascular coagulation [64]. Generally, in animals given antibody to TNF or IL-1 receptor antagonist (IL-1 ra), an attenuation and/or blockade of many pathophysiological changes is associated with activation of the coagulation cascade mediated by endothelial cells and cytokines $[65,66]$.

\section{The Cytokine Network}

Monocytic cells appear to have a pivotal role in mediation of the biological effects of LPS (figure 2). First, LPS can be removed from the blood and detoxified by monocytesevents of benefit to the host [67]. Second, LPS-stimulated monocytes produce cytokines such as TNF and IL-1. Several binding sites for LPS on the macrophage surface have been described [68]. LPS can also interact with monocytes after binding to plasma molecules. An acute-phase protein called LPS-binding protein (LBP) has been shown to bind to the lipid A moiety of LPS [69]. LPS-LBP is a ligand for the CD14 receptors on monocytes and macrophages [70]. Furthermore, a soluble form of the CD14 receptor in serum has been shown to promote the binding of LPS to endothelial cells and to stimulate these cells to produce cytokines and adhesion molecules $[71,72]$. The role played by soluble CDI 4 in vivo is still unknown. When complexed with LBP and attached to monocytes, LPS can stimulate the production of TNF by macrophages at concentrations far below those required for stimulation by LPS alone [69, 70, 73]. Recently, another active component of human plasma, septin, has been described; septin may share with LBP the capacity to enhance the presentation of low concentrations of LPS to monocytes [74]. This information suggests that recognition of the presence of LPS in plasma is important for an effective response to infection with gram-negative bacteria. Therefore, a principal function of LBP/septin may be to enhance the ability of the host to detect LPS early in infection $[69,70$, 74]. No information is available on the role of LBP/septin or CD 14 in vivo, but studies of the blocking of LBP or CD 14 in experimental models will help to define the early steps of interaction of LPS and monocytes in the development of shock.

Bactericidal/permeability-increasing protein (BPI), a protein that has significant amino acid sequence homology with LBP (figure 2), appears to have therapeutic potential; it is found in PMN azurophilic granules that bind to lipid $A$ and LPS in a way similar to that documented for LBP. BPI is an antagonist of $L B P$ because it inhibits rather than amplifies the activity of LPS. In addition, BPI has been shown to inhibit the limulus lysate assay mediated by LPS or the LPSinduced production of cytokines in blood [75, 76]. Experiments in animals challenged with endotoxin and gram-negative bacteria are now planned with a cloned recombinant protein [77], and preliminary data on BPI-mediated protection of mice challenged with LPS have been presented [78].

The intravascular activation of inflammatory systems involved in septic shock is mainly the consequence of an overproduction of various cytokines. Several cytokines are produced not only by macrophages but also by lymphocytes, endothelial cells, and other cells stimulated by microbial products. The systemic release of large amounts of cytokines is associated with death from septic shock in humans [79-81].

TNF is regarded as a central mediator of the pathophysiological changes associated with the release of LPS and possibly with shock caused by microorganisms that do not contain LPS. In animal models, antibodies to TNF-given either prophylactically (before intravenous bolus injections of LPS or gram-negative bacteria) or therapeutically (after challenge)-have effectively increased the rate of survival. A potentially important advantage of making TNF (rather than endotoxin) a target in intervention strategies in patients is its possible role in the pathogenesis of shock caused by grampositive bacteria. For example, septicemia associated with group A Streptococcus is clinically indistinguishable from "classic" gram-negative septic shock [82]. Cell-free supernatants from cultures of gram-positive bacteria have been shown to induce the release of TNF from human peripheralblood monocytes in vitro [83], and concentrations of TNF in the serum of patients with gram-positive sepsis are as high as those in the serum of patients with gram-negative sepsis [84]. However, antibodies to TNF have not been universally effective in models of gram-positive sepsis [85-87].

Cytokines other than TNF are involved in the induction of a shock-like state in animals. Considerable interest has also been focused on IL-I as a mediator of shock and of the associated "acute-phase" responses [65]. Circulating levels of IL$I$ are elevated in shock; together with elevated levels of TNF, these increased levels of IL-1 correlate with the severity of disease. Direct proof of the central role of $1 \mathrm{~L}-1$ in septic shock comes from experiments with animals in which specific blocking of the binding of IL-1 to its cell receptor by 
IL-I ra prevented the detrimental effects of inoculation of LPS or E. coli [88-90].

The overlap of proinflammatory functions and the synergy of TNF and IL-1 are probably important clues to the pathogenesis of septic shock. The administration of low doses of IL-1 does not mediate severe shock and tissue injury; when IL-1 is combined with TNF, however, the former increases the toxicity of the latter [91]. More important, LPS itself potentiates the lethal effects of TNF [92]. Interferon $\gamma$ has also been implicated in the synergy of TNF and IL-1 [93]. Since several cytokines are probably involved in the pathogenesis of septic shock, blocking of TNF alone may not be sufficient to reverse the relevant conditions; therefore, pharmacotherapeutic "cocktails" may prove necessary.

The elucidation of these pathophysiological events has prompted the development of strategies to counteract excessive production or release of TNF and IL-1 and hence to prevent or treat septic shock. Many studies have indicated that such therapy is beneficial in animals (including mice, rats, pigs, rabbits, and baboons). However, other important observations regarding potential therapeutic strategies must be considered. First, TNF, IL-1, and other cytokines are released into the bloodstream during the first hour after bolus injection of LPS or live bacteria; TNF disappears rapidly from the circulation thereafter-several hours before the animal's death [94]. An identical pattern has been found in children with fulminant meningococcemia [80]. Should it be documented in most cases of septic shock in humans, this pattern would suggest that levels of TNF may be elevated before shock develops. If so, then perhaps antibodies to TNF could not be administered soon enough to effectively treat patients with full-blown shock.

Moreover, intravenous bolus challenge in animal models and the fulminant course of meningococcal septicemia in children may not reflect most of the clinical situations in which septic shock develops. In most typical cases, a focus of infection may be present for hours or days and may cause the release of LPS or bacteria to be more sustained and subacute than during fulminant shock. Indeed, when serum concentrations of TNF and other cytokines were measured prospectively in 70 patients with septic shock, levels of TNF and IL-1 were rather low and were detectable for up to 10 days after the onset of shock in patients who ultimately died [81]. These results indicate that concentrations of TNF and other cytokines are sustained in patients presenting with gram-negative shock-a picture unlike that seen after LPS or bacterial challenge in animal models, in which these concentrations are elevated and transient. Moreover, experimental models of severe, subacute, focal gram-negative bacterial infection have exhibited a pattern of TNF release different from that observed after bolus injection, and antibodies to TNF have failed to prevent death in these models [95-97]. Thus the release of TNF in most clinical cases of septic shock is probably different from that in fulminant gram-negative infections, and anticytokine therapies should be devised accordingly.

In such anticytokine therapies, the role of cytokines as a defense against infection must be taken into account. TNF, IL-1, and other cytokines participate in the defense of the host; they are mediators that increase natural resistance by, for example, upregulating the cytolytic activity of lymphocytes and the expression of complement receptors, enhancing the oxidative burst of neutrophils, activating macrophages, and stimulating the proliferation of B cells, T cells, and progenitor cells. Indeed, while mice rendered deficient in the 55-kD receptor for TNF became resistant to challenge with endotoxin, they meanwhile became extremely sensitive to infection with Listeria monocytogenes [98]. Thus the blocking of cytokines in patients with septic shock for the purpose of counteracting "harmful" concentrations may interfere with the control of infection by physiological concentrations. As a result, the infections causing septic shock may worsen, or the patient may become more susceptible to secondary infections.

Two major clinical studies of the blocking of cytokines are in progress, the first examining a murine antibody to TNF and the second evaluating IL-I ra. Preliminary results indicate that anticytokine reagents may have detrimental effects in subgroups of patients; however, it is not known whether the failure observed in patients not presenting with shock is due specifically to a deleterious effect of these reagents on the host defenses against intracellular pathogens. When further results become available, the cause of the deaths of patients in the various subgroups will be analyzed.

The large-scale clinical trial of murine antibody to TNF was initiated in patients presenting with sepsis syndrome and septic shock. While interim analyses revealed a beneficial (although statistically insignificant) effect of treatment on mortality among patients with septic shock, a deleterious effect was found in some patients with sepsis syndrome [99]a less classic form of the cascade of events that leads to death from infection. As a result, this study was discontinued, and a new trial of antibody to TNF including only patients with septic shock is being planned.

The results of the phase 3 trial of IL-1 ra have recently been presented [100]. This randomized, double-blind, placebo-controlled, multicenter clinical trial included $901 \mathrm{pa}^{-}$ tients with sepsis syndrome and septic shock. At enrollment, patients were randomized to receive either an intravenous loading dose of IL-1 ra (100 mg) or placebo, which was followed by a continuous 72 -hour intravenous infusion of ILl ra $(1 \mathrm{mg} /[\mathrm{kg} \cdot \mathrm{h}]$ or $2 \mathrm{mg} /[\mathrm{kg} \cdot \mathrm{h}])$ or placebo. Patients were evaluated at 28 days for all-cause mortality. Treatment with IL-1 ra did not significantly improve the rate of survival, which was the primary end point of the study. However, an individual patient/risk assessment approach, which took into account the APACHE III classification system and specific risk factors for sepsis, was used to analyze outcome as a sec- 
ondary end point [101]. With this new method of risk prediction, treatment with IL-1 ra appeared to be beneficial for patients with a mortality risk of $>0.24$ but not for those with a mortality risk of $<0.24$.

Both of these studies aimed at inhibiting cytokines. The results suggest that, while this approach may be useful for the most severely affected patients, it is potentially harmful to patients who are less severely affected. Obviously, these findings need to be confirmed, and the subgroup of patients who might benefit from these therapies needs to be precisely delineated. The results of the IL-I ra study suggest that defining the risk of death at the time of intervention-rather than at the time of clinical presentation-may be a simple tool for identifying such patients.

Soluble forms of cytokine receptors offer an alternative approach to the blocking of cytokines. The potential of this approach was shown in experiments and clinical studies with IL-1 ra; soluble TNF receptors may also be of value (figure 2 ). These receptors inhibit the bioactivity of TNF in vivo $[102,103]$. Furthermore, it has recently been shown that mice deficient in the 55-kD TNF receptor are resistant to endotoxic shock [98]. Clinical trials with soluble TNF receptors are therefore being planned.

Currently, two other cytokines, IL- 8 and IL-10, are being evaluated as possibly important mediators in shock. IL- 8 has been characterized primarily as a PMN chemoattractant and a proinflammatory mediator; it has been detected in healthy volunteers after intravenous injection of endotoxin [104] and in patients with gram-negative shock [105]. Its precise role in vivo has not yet been fully elucidated. Recently, the anti-inflammatory IL-10 has been suggested as a candidate for treatment of bacterial sepsis. IL-10 was found to decrease the production of IL-1, IL-6, and TNF in vitro and to suppress cytokines and provide protection in mice challenged with lethal doses of endotoxin [106, 107]. It is interesting that protection was documented when the administration of IL-10 was delayed after LPS challenge-an effect that is hardly evident with antibodies to TNF. To investigate the potential of IL- 10 as a candidate for the treatment of bacterial sepsis, these preliminary results in endotoxemia should now be extended to bacterial infections.

Finally, as has been mentioned, the synergy that exists among cytokines (especially TNF and IL-1) and between cytokines and cell wall fragments (mainly TNF and LPS) suggests that a combined approach aimed at blocking various triggers and mediators may have the greatest potential for improving the outcome of septic shock.

\section{Conclusion}

Several approaches to the treatment and prevention of septic shock that are now being considered aim to suppress and/or inhibit one or another of a range of cytokines and other inflammatory mediators. However, since the syndrome most likely results from complex interactions involving all these pathways and cytokines, the roles that each mechanism plays in the pathogenesis of septic shock must be delineated. This information will help to identify the subsets of patients who might benefit from the administration of antibodies to endotoxin and cytokines and to ascertain the need for other cytokine inhibitors or anti-inflammatory agents.

\section{References}

1. Bone RC. Sepsis, the sepsis syndrome, multi-organ failure: a plea for comparable definitions. Ann Intern Med 1991:114:332-3.

2. Bone RC, Fisher CJ, Clemmer IP. Slotman GJ, Metz GA, Balk RA. A controlled clinical trial of high-dose methylprednisolone in the treatment of severe sepsis and septic shock. N Engl J Med 1987:317:653-8

3. Bone RC. Sprung CL, Sibbald WJ. Definitions for sepsis and organ failure. Crit Care Med 1992;20:724-6.

4. Ispahani P, Pearson NJ. Greenwood D. An analysis of community and hospital-acquired bacteremia in a large teaching hospital in the United Kingdom. Q J Med 1987;241:427-40.

5. Calandra T, Glauser MP. Schellekens J, Verhoef J, the Swiss-Dutch J5 Immunoglobulin Study Group. Treatment of gram-negative septic shock with human $\operatorname{IgG}$ antibody to Escherichia coli 15 : a prospective, double-blind, randomized trial. J Infect Dis 1988;158:312-9

6. Brandtzaeg P. Kierulf P. Gaustad P. et al. Plasma endotoxin as a predictor of multiple organ failure and death in systemic meningococcal disease. J Infect Dis 1989;159:195-204.

7. Galanos C. Freudenberg MA. Matsuura M. Mechanisms of the lethal action of endotoxin and endotoxin hypersensitivity. In: Friedman H. Klein TW. Nukano M, Nowotny A, eds. Endotoxin: advances in experimental medicine and biology. New York: Plenum Press. 1990:603-19.

8. Stït7 $P$, Liehl E. Lipid $A$ analogs aimed at preventing the detrimental effects of endotoxin. Infect Dis Clin North Am 1991:5:847-74.

9. Lynn WA, Golenbock DT. Lipopolysaccharide antagonists. Immunol Today 1992:13:271-6.

10. Ziegler EJ, McCutchan JA. Fierer J, et al. Treatment of gram-negative bacteremia and shock with human antiserum to a mutant Escherichia coli. N Engl J Med 1982;307:1225-30.

11. Baumgartner JD, Glauser MP, McCutchan JA, et al. Prevention of gram-negative shock and death in surgical patients by prophylactic antibody to endotoxin core glycolipid. Lancet 1985;2:59-63.

12. J5 Study Group. Treatment of severe infectious purpura in children with human plasma from donors immunized with Escherichia colt J5: a prospective double-blind study. J Infect Dis 1992:165:695701.

13. McCutchan JA. Wolf JL. Ziegler EJ. Braude Al. Ineffectiveness of single-dose human antiserum to core glycolipid ( $E$. coli J5) for prophylaxis of bacteremic, gram-negative infections in patients with prolonged neutropenia. Schweiz Med Wochenschr 1983:113 (Suppl 14):40-5

14. Greenman RL, Schein RM. Martin MA, et al. A controlled clinical trial of $\mathrm{E} 5$ murine monoclonal $\operatorname{lgM}$ antibody to endotoxin in the 1reatment of gram-negative sepsis. The XOMA Sepsis Study Group. JAMA 1991:266: 1097-102.

15. Ziegler EJ, Fisher CJ. Sprung CL. et al. Treatment of gram-negative bacteremia and septic shock with HA-1A human monoclonal antibody against endotoxin. A randomized, double-blind, placebo-controlled trial. N F.ngl J Med 1991;324:429-36.

16. Wenzel R, Bone R, Fein A, et al. Results of a second double-blind, randomized, controlled trial of antiendotoxin antibody $E 5$ in gram- 
negative sepsis [abstract no 1170]. In: Program and abstracts of the 3 Ist Interscience Conference on Antimicrobial Agents and Chemotherapy (Chicago). Washington, DC: American Society for Microbiology, 1991.

17. Warren HS, Danner RL, Munford RS. Anti-endotoxin monoclonal antibodies. N Engl J Med 1992;326:1153-7.

18. Kolata G. At market's edge: how a $\$ 1$ billion drug fell flat. The New York Times, 15 March 1993:A20.

19. Heumann D. Baumgartner JD, Jacot-Guillarmod H, Glauser MP. Antibodies to core lipopolysaccharide determinants: absence of crossreactivity with heterologous lipopolysaccharides. J Infect Dis 1991;163:762-8.

20. Baumgartner JD, Heumann D, Calandra T, Glauser MP. Antibodies to lipopolysaccharides after immunization of humans with the rough mutant Escherichia coli J5. J Infect Dis 1991;163:769-72.

21. Fujihara Y, Lei MG, Morrison DC. Characterization of specific binding of a human immunoglobulin $M$ monoclonal antibody to lipopolysaccharide and its lipid A domain. Infect Immun 1993;61: 910-8.

22. Mascelli MA, Frederick B, Ely T, et al. Reactivity of the human antiendotoxin immunoglobulin $\mathrm{M}$ monoclonal antibody $\mathrm{HA}-1 \mathrm{~A}$ with lipopolysaccharides from rough and smooth gram-negative organisms. Infect Immun 1993;61:1756-63.

23. Baumgartner JD. Immunotherapy with antibodies to core lipopolysaccharide: a critical appraisal. Infect Dis Clin North Am 1991;5: 915-27.

24. Krieger JI, Fletcher RC, Siegel SA, et al. Human anti-endotoxin antibody HA-IA mediates complement-dependent binding of Escherichia coli $\mathrm{J} 5$ lipopolysaccharide to complement receptor type $\mathrm{I}$ of human erythrocytes and neutrophils. J Infect Dis 1993;167:86575.

25. Tonoli M, Davies KA, Norsworthy PJ, Cohen J, Walport MJ. The anti-lipid A antibody HA-1A binds to rough gram-negative bacteria, fixes complement and facilitates binding to erythrocyte CR I (CD35). Clin Exp Immunol 1993;92:232-8.

26. Wood DM, Parent JB. Gazzano-Santaro H, et al. Reactivity of monoclonal antibody $E 5$ with endotoxin. I. Binding to lipid $A$ and rough lipopolysaccharides. Circ Shock 1992;38:55-62.

27. Parent JB, Gazzano-Santoro H, Wood DM, et al. Reactivity of monoclonal antibody E5 with endotoxin. II. Binding to short- and longchain smooth lipopolysaccharides. Circ Shock 1992;38:63-73.

28. Warren HS, Amato SF, Fitting C, et al. Assessment of ability of murine and human anti-lipid $A$ monoclonal antibodies to bind and neutralize lipopolysaccharide. J Exp Med 1993;177:89-97.

29. Teng NNH, Kaplan HS. Hebert JM. et al. Protection against gramnegative bacteremia and endotoxemia with human IgM antibodies. Proc Natl Acad Sci USA 1985;82:1790-4.

30. Baumgartner JD, Heumann D, Gerain J, Weinbreck P, Grau GE, Glauser MP. Association between protective efficacy of anti-lipopolysaccharide (LPS) antibodies and suppression of LPS-induced tumor necrosis factor $\alpha$ and interleukin 6. Comparison of $O$ side chain-specific antibodies with core LPS antibodies. J Exp Med 1990;171:889-96.

31. Cornelissen JJ, Mäkel I, Algra A, et al. Protection against lethal endotoxemia by anti-lipid A murine monoclonal antibodies: comparison of efficacy with that of human anti-lipid $A$ monoclonal antibody HA-1A. J Infect Dis 1993;167:876-81.

32. Quezado ZMN. Natanson C. Alling DW, et al. A controlled trial of HA-1A in a canine model of gram-negative septic shock. JAMA 1993;269:2221-7.

33. Young LS, Gascon R, Alam S, Bermudez LEM. Monoclonal antibodies for treatment of gram-negative infections, Rev Infect Dis 1989;11(suppl 7):S1564-71.
34. Romulo RLC, Palardy JE, Opal SM. Efficacy of anti-endotoxin monoclonal antibody E5 alone or in combination with ciprofloxacin in neutropenic rats with Pseudomonas sepsis. J Infect Dis 1993;167: 126-30.

35. Rothstein JL, Schreiber H. Tissue damage caused by TNF and complement. Immunol Ser 1992;56:453-81.

36. Jacobs HS. The role of activated complement and granulocytes in shock states and myocardial infarction. J Lab Clin Med 1981;98:645-54.

37. Hack CE, Nuijens JH, Felt-Bersma RJF, et al. Elevated plasma levels of the anaphylatoxins $\mathrm{C} 3 \mathrm{a}$ and $\mathrm{C} 4 \mathrm{a}$ are associated with a fatal outcome in sepsis. Am J Med 1989;86:20-6.

38. Reines HD, Halushka PV, Cook JA, Wise WC, Rambo W. Plasma thromboxane concentrations are raised in patients dying with septic shock. Lancet 1982;2:174-5.

39. Welbourn CRB, Young Y. Endotoxin, septic shock, and acute lung injury: neutrophils, macrophages, and inflammatory mediators. $\mathrm{Br}$ J Surg 1992;79:998-1003.

40. Springer TA. Adhesion receptors of the immune system. Nature 1990;346:425-34.

41. Saukkonen K, Sande S, Cioffe C, et al. The role of cytokines in the generation of inflammation and tissue damage in experimental gram-positive meningitis. J Exp Med 1990;171:439-48.

42. Chang SW, Fedderson CO, Henson PM, et al. Platelet-activating factor mediates hemodynamic changes and lung injury in endotoxintreated rats. J Exp Med 1990;171:439-48.

43. Doebber TW, Wu MS, Robbins JC, et al. Platelet activating factor (PAF) involvement in endotoxin-induced hypotension in rats. Studies with PAF-receptor antagonist kadsurenone. Biochem Biophys Res Commun 1985;127:799-808.

44. Anderson BO, Bensard DD, Harken AH. The role of platelet activating factor and its antagonists in shock, sepsis and multiple organ failure. Surg Gynecol Obstet 1991;172:415-24.

45. Dhainaut JF, Tenaillon A, Letzulo Y, et al. Efficacy of P.A.F. antagonist (BN 52021) in reducing mortality of patients with severe gramnegative sepsis. Circ Shock 1993; Suppl 1:42.

46. Nathan C. Nitric oxide as a secretory product of mammalian cells. FASEB J 1992;6:3051-64.

47. Vane JR, Angaard EE, Botting RM. Regulatory functions of the vascular endothelium. N Engl J Med 1990;323:27-36.

48. Hotchkiss RS, Parker JL, Adams HR. Inhibition of NO synthesis in septic shock. Lancet 1992;339:434-5.

49. Evans T, Carpenter A, Silva A, Cohen J. Differential effects of monoclonal antibodies to tumor necrosis factor alpha and gamma interferon on induction of hepatic nitric oxide synthase in experimental gram-negative sepsis. Infect Immun 1992;60:4133-9.

50. Evans TE, Carpenter A, Kinderman H, et al. Evidence of increased nitric oxide production in patients with the sepsis syndrome. Circ Shock 1993 (in press).

51. Shultz PJ, Raij L. Endogenously synthesized nitric oxide prevents endotoxin-induced glomerular thrombosis. J Clin Invest 1992;90: 1718-25.

52. Teale DM, Atkinson AM. Inhibition of nitric oxide synthesis improves survival in a murine peritonitis model of sepsis that is not cured by antibiotics alone. J Antimicrob Chemother 1992;30: $839-42$.

53. Cobb JP, Natanson $\mathrm{C}$, Hoffman WD, et al. $\mathrm{N}$ omega amino-L-arginine, an inhibitor of nitric oxide synthase, raises vascular resistance but increases mortality in awake canines challenged with endotoxin. J Exp Med 1992; 176:1175-82.

54. Petros A, Bennett D. Vallance P. Effect of nitric oxide synthetase inhibitors on hypotension in patients with septic shock. Lancet 1991;338:1557-8. 
55. Kalter ES, van Dijk WC. Timmerman A. Verhoef J. Bouma BN. Activation of purified human plasma prekallikrein triggered by cell wall fractions of Escherichia coli and Staphylococcus aureus. J Infect Dis 1983; 148:682-91.

56. Spika JS, Peterson PK. Wilkinson BJ, et al. Role of peptidoglycan from Staphylococcus aureus in leukopenia, thrombocytopenia. and complement activation associated with bacteremia. J Infect Dis 1982;146:227-34

57. Colman RW. The role of plasma proteases in septic shock. N Engl J Med 1989;320:1207-9.

58. Pixley RA, De La Cadena R, Page JD, et al. The contact system contributes to hypotension but not disseminated intravascular coagulation in lethal bacteremia. In vivo use of a monoclonal anti-factor XII antibody to block contact activation in baboons. J Clin Invest 1993;91:61-8.

59. Warr TA, Rao LV, Rapaport SI. Disseminated intravascular coagulation in rabbits induced by administration of endotoxin or tissue factor: effect of anti-tissue factor antibodies and measurement of plasma extrinsic pathway inhibitor activity. Blood 1990;75: $\mid 481-9$.

60. Taylor FB Jr, Chang A, Ruf W, et al. Lethal E. coli septic shock is prevented by blocking tissue factor with monoclonal antibody. Circ Shock 1991;33:127-34.

61. Esmon CT. The regulation of natural anticoagulant pathways. Science 1987;235: 1348-52.

62. Taylor FB, Chang A, Esmon T, et al. Protein C prevents the coagulopathic and lethal effects of Escherichia coll infusion in the baboon. J Clin Invest 1987;79:918-25.

63. Dinarello CA. The proinflammatory cytokines interleukin-1 and tumor necrosis factor and treatment of the septic shock syndrome. J Infect Dis 1991;163:1177-84.

64. Cotran RS, Pober IS. Effects of cytokines on vascular endothelium: their role in vascular and immune injury. Kidney Int 1989;35: 969-75.

65. Dinarello CA. Interleukin-I and interleukin-I antagonism. Blood 1991;77:1627-52.

66. Tracey KJ, Lowry SF. The role of cytokine mediators in septic shock. Adv Surg 1990;23:21-56.

67. Munford RS. Hall CL. Uptake and deacylation of bacterial lipopolysaccharides by macrophages from normal and endotoxin-hyporesponsive mice. Infect Immun 1985;48:464-73.

68. Lei MG, Chen TY, Morrison DC. Lipopolysaccharide/lipid A receptors on lymphocytes and macrophages. Int Rev Immunol 1990;6:223-35.

69. Schumann RR, Leong SR, Flaggs GW, et al. Structure and function of lipopolysaccharide binding protein. Science 1990;249:1429-31.

70. Wright SI, Ramos RA, Tobias PS, Ulevitch RJ, Mathison JC. CD 4 , a receptor for complexes of lipopolysaccharide (LPS) and I.PS binding protein. Science 1990;249:1431-3.

71. Frey EA, Miller DS, Jahr TG, et al. Soluble CD14 participates in the response of cells to lipopolysaccharide. J Exp Med 1992;176: 1665-71.

72. Pugin J, Schürer-Maly CC. Letureq D, et al. Lipopolysaccharide activation of human endothelial and epithelial cells is mediated by lipopolysaccharide-binding protein and soluble CD/4. Proc Natl Acad Scj USA 1993;90:2744-8.

73. Heumann D, Gallay P, Barras C, et al. Control of lipopolysaccharide (LPS) binding and LPS-induced tumor necrosis factor secretion in human peripheral blood monocytes. J Immunol 1992;148:350512.

74. Wright SD, Ramos RA, Patel M, et al. Septin: a factor in plasma that opsonizes lipopolysaccharide-bearing particles for recognition by CD14 on phagocytes. J Exp Med 1992;176:719-27.
75. Ooi CE. Weiss J, Doerfler ME. Elsbach P. Endotoxin-neutralizing properties of the $25 \mathrm{kD} \mathrm{N}$-terminal fragment and a newly isolated $30 \mathrm{kD}$ C-terminal fragment of the $55-60 \mathrm{kD}$ bactericidal/ permeability-increasing protein of human neutrophils. J Exp Med $1991 ; 174: 649-55$

76. Marra MN, Wilde CG, Grifth JE. Snable JL, Scott RW. Bactericidal/ permeability-increasing protein has endotoxin-neutralizing activity. J Immunol 1990;144:662-6

77. Weiss J, Elsbach P. Shu C, et al. Human bactericidal/permeabilityincreasing protein and a recombinant NH2-terminal fragment cause killing of serum-resistant gram-negative bacteria in whole blood and inhibit tumor necrosis factor release induced by the bacteria. J Clin Invest 1992;90: I 122-30.

78. Opal SM. Bactericidal/permeability-increasing protein as an endogenous anti-endotoxin molecule. Circ Shock 1993; Suppl 1:47.

79. Girardin E, Grau GE, Dayer JM, Roux-Lombard P, Lambert PH Tumor necrosis factor and interleukin-1 in the serum of children with severe infectious purpura. N Engl J Med 1988;319:397-400

80. Waage A. Halstensen A, Espevik T. Association between tumor necrosis factor in serum and fatal outcome in patients with meningococcal disease. Lancet 1987;1:355-7.

81. Calandra T, Baumgartner JD. Grau GE, et al. Prognostic values of tumor necrosis factor/cachectin. interleukin-I, interferon-alpha and interferon-gamma in the serum of patients with septic shock. Swiss-Dutch J5 Immunoglobulin Study Group. J Infect Dis 1990;161:982 -7

82. Stevens DL, Tanner MH, Winship J, et al. Severe group A streptococcal infections associated with a toxic shock-like syndrome and scarlet fever toxin A. N Engl J Med 1989;321:1-7.

83. Bayson KF, Tomlinson M, Cohen J. In vitro stimulation of TNF- $\alpha$ from human whole blood by cell-free supernatants of gram positive bacteria. Cytokine 1992;4:397-402.

84. Marks JD, Marks CB, Luce JM, et al. Plasma tumor necrosis factor in patients with septic shock. Mortality rate, incidence of adult respiratory distress syndrome. and effects of methylprednisolone administration. Am Rev Respir Dis 1990;141:94-7.

85. Wayte J, Silva AT, Krausz T, et al. Observations on the role of TNF in a murine model of shock due to Sireptococcus progenes. Crit Care Med 1993 (in press)

86. Martin RA. Silva AT, Cohen J. Effect of anti-TNF alpha treatment in an antibiotic treatment model of shock due to Sireptococcus pyo genes. FEMS Microbiol Lett 1993 (in press).

87. Hinshaw LB, Emerson TE Jr, Taylor FB Jr, et al. Lethal Staphylococcus aureus-induced shock in primates: prevention of death with anti-TNF antibody. J Trauma 1992;33:568-73.

88. Mclntyre KW, Stepan GJ, Kolinsky KD, et al. Inhibition of interleukin I (IL-1) binding and bioactivity in vitro and modulation of acute inflammation in vivo by IL-1 receptor antagonist and anti-IL I receptor monoclonal antibody. J Exp Med 1991:173:931-9.

89. Wakabayashi G, Gelfand JA, Burke JF, Thompson RC, Dinarello CA. A specific receptor antagonist for interleukin 1 prevents Escherichia coli-induced shock in rabbits. FASEB J 1991:5:338-43.

90. Alexander HR. Doherty GM, Buresh CM, et al. A recombinant human receptor antagonist to interleukin 1 improves survival after lethal endotoxemia in mice. J Exp Med 1991;173:1029-32

91. Waage A, Espevik T. Interleukin 1 potentiates the lethal effect of tumor necrosis factor-alpha/cachectin in mice. J Exp Med 1988; 167:1987-92.

92. Rothstein IL, Schreiber H. Synergy between tumor necrosis factor and bacterial products causes hemorrhagic necrosis and lethal shock in normal mice. Proc Natl Acad Sci USA 1988;85:607-11

93. Billiau A. Gamma-interferon: the match that lights the fire? Immunol Today 1988;9:37-40. 
S216

Glaser et al.

CID 1994;18 (Suppl 2)

94. Michie HR, Manogue KR, Sprogs DR, et al. Detection of circulating tumor necrosis factor after endotoxin administration. $\mathrm{N}$ Eng $\mathrm{J}$ Med 1988;318:1481-6.

95. Baby GJ, Plessala KJ, Wilson LA, Thompson JJ, Nelson S. Divergent efficacy of antibody to tumor necrosis factor- $\alpha$ in intravascular and peritonitis models of sepsis. J Infect Dis 1991;163:83-8.

96. Echtenacher B, Folk W, Männel DN, Kramer PH. Requirement of endogenous tumor necrosis factor/cachectin for recovery from experimental peritonitis. J Immunol 1990;145:3762-6.

97. Zanetti G, Human D, Grain J, et al. Cytokine production after intravenous or peritoneal gram negative bacterial challenge in mice. Comparative protective efficacy of antibodies to tumor necrosis factor-alpha and to lipopolysaccharide. J Immunol 1992;148:1890-7.

98. Prefer K, Matsuyama T, Kündig TM, et al, Mice deficient for the 55 $\mathrm{kD}$ tumor necrosis factor receptor are resistant to endotoxic shock, yet succumb to $L$. monocytogenes infection. Cell 1993;73:457-67.

99. Cross AS. Biotech strategies for treatment of sepsis. Endotoxin Newsletter 1993;3:2-3.

100. Fisher CJ. Slotman GJ, Opal SM, et al. Human recombinant interleukin-1 receptor antagonist (IL-1 ra) in the treatment of patients with sepsis syndrome. Cire Shock 1993: Suppl 1:42.
101. Knaus W, Hazel F, Fisher CJ, et al. An individual patient risk assessmont approach to design and analysis of clinical trials for patients with sepsis and organ failure. Cire Shock 1993; Suppl 1:14.

102. Ashkenazi A, Marsters SA, Capon DJ, et al. Protection against endotoxin shock by a tumor necrosis factor receptor immunoadhesion. Proc Natl Acad Sci USA 1991;88:10535-9.

103. Lesslauer W, Tabuchi H, Gentz R, et al. Recombinant soluble tumor necrosis factor receptor proteins protect mice from lipopolysaccharide-induced lethality. Eur J Immunol 1991;21:2883-6.

104. Martich GD, Banner RL. Ceska M, Suffredini AF. Detection of interleukin 8 and tumor necrosis factor in normal humans after intravenous endotoxin: the effect of antiinflammatory agents. J Exp Med 1991;173:1021-4.

105. Halstensen A, Cesta M, Brandtzaeg P, Red H, Noes A, Wage A. Interleukin -8 in serum and cerebrospinal fluid from patients with meningococcal disease. J Infect Dis 1993;167:471-5.

106. Howard M, Muchamuel T, Andrade S, Menon S. Interleukin 10 protets mice from lethal endotoxemia. J Exp Med 1993;177:1205-8.

107. Gerard C. Bruyns C. Marchant A, et al. Interleukin 10 reduces the release of tumor necrosis factor and prevents lethality in experimental endotoxemia. J Exp Med 1993;177:547-50. 